\title{
Determination of maximum crack width in two-way reinforced concrete slabs
}

\author{
P. DESAYI \& A. B. KULKARNI
}

Dr A. W. Beeby, Design Research Department, Cement and Concrete Association The Authors have made an interesting attempt to re-interpret the test data produced by Nawy et al. ${ }^{1-3}$ In order to be able to judge the merits of this new interpretation, it appears useful to try to answer two questions. First, what accuracy should one expect from a crack prediction formula? Second, does this new interpretation fit the facts better than Nawy's own interpretation of his data?

26. In order to answer the first question, it is useful to attempt to establish some overall measure by which to judge the ability of a proposed calculation method to reflect the influence of the various parameters which may affect behaviour. One approach which can give a simple measure of this is to compare the distribution of the errors produced by a particular formula (exp-calc) with the distribution of the original data. For example, consider Nawy's results for slabs having a steel stress of $60 \mathrm{kip} / \mathrm{sq}$. in. The mean of all the measured cracks widths on all the slabs used by the Authors is $0.03789 \mathrm{in}$., and the standard deviation of these results is 0.01576 , giving a coefficient of variation of 0.416. This is equivalent to saying that, if all variables are ignored and the crack width is simply assumed to have a constant value of 0.03789 , the coefficient of variation of exp-calc will be 0.416. A formula which purports to take account of any variables within the test program must, to have any predictive value, give a significantly lower coefficient of variation than this. There is also a lower limit to the accuracy which a formula can achieve; this is defined by the inherent variability of the phenomenon considered and can be found by comparing the variability between identical specimens. A rough estimate of this for Nawy's slabs gives a coefficient of variation of $0 \cdot 13$. Thus the ideal formula would give a coefficient of variation of 0.13 and any formula giving a coefficient of variation of 0.4 or more has no predictive value. The Authors obtain a coefficient of variation of 0.41 for the case considered. Table 3 gives values for the variability of Nawy's data at the rest of the stress levels considered. It can be seen that, although for lower stress levels the coefficients in Table 2 are slightly below the values in Table 3, they are generally of the same order, suggesting that the Authors' formula is of little use in predicting the influence on cracking of the variables tested by Nawy.

27. The second question can be answered by reference to Table 4, which is comparable to Table 2 for values of $w_{0 \times \mathrm{g}} / w_{\mathrm{cal}}$, derived using Nawy's own formula. The standard deviations and coefficients of variation are roughly half those given in Table 2. Nawy's formula is thus superior to the Authors' formula by a wide margin. Furthermore, Nawy's formula shows up favourably when tested against the criteria in $\$ 26$. It could be argued that a formula of lesser accuracy is justifiable in practical situations

Paper published: Proc. Instn Civ. Engrs, Part 2, 1976, 61, June, 343-349. 
Table 3. Variability of Nawy's data

\begin{tabular}{c|c}
$\begin{array}{c}\text { Steel } \\
\text { stress }\end{array}$ & $\begin{array}{c}\text { Coefficient of variation } \\
\text { of data }\end{array}$ \\
\hline 20 & 0.500 \\
30 & 0.479 \\
35 & 0.467 \\
50 & 0.449 \\
60 & 0.416 \\
\hline
\end{tabular}

Table 4. Values of $w_{\text {exp }} / w_{\text {calc }}$ at various stress levels in steel for 72 slabs using Nawy's formula ${ }^{3}$

\begin{tabular}{c|c|c|c}
\hline $\begin{array}{c}\text { Stress in } \\
\text { reinforcement, } \\
\text { kip/sq. in. }\end{array}$ & Average & $\begin{array}{c}\text { Standard } \\
\text { deviation }\end{array}$ & $\begin{array}{c}\text { Coefficient of } \\
\text { variation }\end{array}$ \\
\hline 20 & 0.953 & 0.22 & 0.23 \\
30 & 0.940 & 0.20 & 0.21 \\
35 & 0.967 & 0.21 & 0.22 \\
50 & 1.025 & 0.24 & 0.24 \\
60 & $1 \cdot 141$ & 0.30 & 0.26 \\
\hline
\end{tabular}

if it is simpler to apply but the Authors' formula is, if anything, more complicated than Nawy's.

28. Consideration of these two questions must call the validity and usefulness of the proposed formula into question.

29. The applicability of Nawy's tests to practical situations should also be considered. He used model slabs roughly $1.5-1.8 \mathrm{~m}$ square and about $75 \mathrm{~mm}$ thick. They were mainly reinforced with welded mesh made from hard drawn wire. Two distinct types of cracking were observed: an orthogonal pattern of cracks which followed the lines of the reinforcement (i.e. the cracks all formed over the wires) and, for low percentages of reinforcement, cracks formed along only what eventually developed into the yield lines. Nawy explained this behaviour on the assumption that force was transferred from steel to concrete mainly at the welds in the mesh. This is probably reasonable for drawn wire because it has a much lower bond strength than normal rolled reinforcing bars. With certain weld spacings, cracks are induced at all welds; with larger spacings, insufficient force was transferred from the steel to the concrete to generate spread cracking and only the yield line formed. These types of behaviour are not typical of the behaviour of slabs reinforced with normal bar reinforcement ${ }^{6}$ and there is thus little reason to expect Nawy's results to be applicable to normal reinforced concrete slabs.

Dr B. V. Subrahmanyam and Mr K. Ganesh Babu, Structural Engineering Research (Regional) Centre. Madras

Yield line and strip methods are being incorporated in the codes of practice of various countries. This will result in a reduction of the reinforcing steel and increase in the stresses under service loads. The problem of cracking and hence of corrosion assumes greater importance in this context. Adequate research has not been published on crack widths in two-way reinforced concrete slabs. The Authors are to be congratulated for their timely contribution on this aspect.

31. The Authors have presented an equation for the prediction of crack widths in two-way slabs considering the bond force on the bars and the anchorage forces due to cross wires. A similar approach was developed by Srinivasa Rao and Subrahmanyam? for one-way slabs reinforced with welded wire fabric. It is good to see that a similar 
approach has been extended to two-way slabs. However, we doubt if the Authors' equation is applicable only to two-way slabs reinforced with welded wire fabric, but believe it is aiso applicable in the case of regular bars. This is not reflected in the Paper.

32. In one-way slabs reinforced with welded fabric ${ }^{7}$ it was observed that the flexural rigidity of the transverse wire plays an important role in deciding if the bearing stress $f_{\mathrm{bb}}$ is uniform and if the entire length $S_{1}$ is effective. However, the Authors have assumed that the entire length $S_{1}$ of the transverse wire will have uniform bearing. Assumptions, without adequate proof, have also been made in the Paper regarding the distribution of the tensile stress on concrete area, bond characteristics of the bars and the bearing stress. It is felt that these assumptions might have contributed considerably to the large differences between the experimental and the calculated maximum crack widths.

33. The experimental maximum crack widths vary from $+45 \%$ to $-45 \%$ of the calculated maximum crack widths. Several points fall out of even this range (see Fig. 2). This is also the case with the equation due to Nawy and Blair ${ }^{3}$ (see their Figs 1.4(a)-(h)). To the design engineer such a large variation may not be acceptable even if the average of the value $w_{\text {exp }} / w_{\text {calo }}$ is very near $1 \cdot 00$.

34. Recognizing the fact that the phenomenon of cracking itself is random, any approach to analyse test data and to calculate maximum crack widths should be associated with a definite probability. The generally accepted probability figure is $95 \%$. We feel that such an approach, if adopted in all crack width studies, would lead to more reliable methods for the prediction of crack widths in two-way slabs.

\section{Dr Desayi and Mr Kulkarni}

The object of the investigation described in the Paper was to arrive at a method which is sufficiently general for determining the crack widths in two-way reinforced concrete slabs and one which does not require the use of different constants for different support and loading conditions. As the test results of $\mathrm{Nawy}^{3}$ were the only results available to us they were analysed on the basis of the proposed method and a higher coefficient of variation was noticed.

36. We are aware that the proposed method gives a large coefficient of variation but wonder whether it would be reasonable to compare the results of Nawy's formula with those of the proposed analysis because Nawy's formula uses different values for the multiplier constant $K$ which are obtained for the best fit of different groups of slabs. They would therefore yield a better agreement for the same test results than a method which is formulated to be applicable to all boundary and loading conditions.

37. An improvement in the prediction by the proposed method can be obtained by empirically modifying the effective concrete area in tension and the expression for $f_{b}$

Table 5. Values of $w_{\text {exp }} / w_{\text {calc }}$ at various stress levels in steel for 72 slabs using equation (9)

\begin{tabular}{c|c|c|c}
\hline $\begin{array}{c}\text { Stress in } \\
\text { reinforcement, } \\
\text { kip/sq. } \text { in. }\end{array}$ & Average & $\begin{array}{c}\text { Standard } \\
\text { deviation }\end{array}$ & $\begin{array}{c}\text { Coefficient of } \\
\text { variation }\end{array}$ \\
\hline 20 & 0.9409 & $0 \cdot 300$ & 0.32 \\
30 & 0.9182 & $0 \cdot 266$ & 0.29 \\
35 & 0.9529 & 0.276 & 0.29 \\
50 & 0.9779 & 0.284 & 0.29 \\
60 & 1.0811 & 0.335 & 0.31 \\
\hline
\end{tabular}


Table 6. Comparison of computed crack widths by proposed method and Nawy's method for flat slabs

\begin{tabular}{c|c|c|c}
\hline Slab & $\begin{array}{c}\text { Experiment crack } \\
\text { width, } \\
\text { in. }\end{array}$ & $\begin{array}{c}w_{\text {calc }} \text { using } \\
\text { proposed method, } \\
\text { in. }\end{array}$ & $\begin{array}{c}w_{\text {calc using }} \\
\text { Nawy's method, } \\
\text { in. }{ }^{*}\end{array}$ \\
\hline 2 & 0.016 & 0.021 & 0.020 \\
3 & 0.016 & 0.024 & 0.023 \\
4 & 0.016 & 0.018 & 0.017 \\
5 & 0.016 & 0.010 & 0.010 \\
7 & 0.016 & 0.019 & 0.018 \\
8 & 0.016 & 0.018 & 0.019 \\
9 & 0.016 & 0.019 & 0.018 \\
& 0.016 & 0.022 & 0.022 \\
\hline
\end{tabular}

- The value of $K R$ in Nawy's equation was taken as $3.0 \times 10^{-5}$ by Hawkins et al. ${ }^{9}$

given by equation (5). Thus, one could rewrite the crack width equation as

$$
w_{\max }=\frac{\alpha R\left(A_{\mathrm{et}}\right)^{m} f_{\mathrm{t}}}{\pi \phi_{1}\left(\frac{M_{\mathrm{cr}}}{M_{\mathrm{u}}}\right)^{n} \frac{f_{\mathrm{ub}}}{S_{1}}+\frac{\phi_{2} f_{\mathrm{t}}}{2 S_{2}}} \epsilon_{\mathrm{s}} \text {. . . . . . . }
$$

where $\alpha, m$ and $n$ are constants to be determined for a statistical best fit of test results. Equation (9) would be dimensionally balanced only with $\alpha$ being assigned suitable dimensions. For certain assigned values $\dagger$ of $m=\frac{1}{2}, n=\frac{1}{4}, \alpha=1.43$ and $f_{\mathrm{ub}}$ given by CP $110^{5}$ without $20 \%$ increase, there is improvement in the prediction of the proposed method $^{8}$ as shown in Table 5 . The coefficients of variation in Table 5 are smaller than those in Table 3 and closer to those in Table 4.

38. Doubts have been expressed as to whether the results of Nawy would be applicable to normal reinforced concrete slabs. This has been looked into by Nawy and Blair $^{3}$ who applied their equations to slabs tested by other investigators and found good agreement between calculated and experimental crack widths.

39. Equation (9) has also been used ${ }^{8}$ to calculate the maximum crack widths in flat slabs reinforced with normal bars reported by Hawkins et al. ${ }^{9}$ Table 6 compares the experimental crack widths of these slabs with those obtained using equation (9) and the method proposed by Nawy. The proposed method and Nawy's method give almost the same result and overestimate the crack widths by $11.5 \%$ on average.

40. We think that $\S 37$ and $\S 39$ show the validity of the proposed approach, although it could be modified further on the lines suggested in $\$ 37$ to make it more useful.

41. We thank Dr Subramanyam and Mr Ganesh Babu for bringing our attention to reference 7 and are pleased to know that, working independently, both groups of investigators have attempted to include the bearing of the transverse bars in the resistance to cracking, although this is effected in different ways in the two studies. The proposed method is designed to be applicable in general to two-way reinforced concrete slabs irrespective of the usage of welded mesh or ordinary reinforcement and the support or loading condition. It is difficult to determine experimentally the values of $k_{\mathrm{t}}, k_{\mathrm{b}}$ and $f_{\mathrm{bb}}$ and hence they can be only assumed. The values assumed in the Paper could have contributed to the greater spread in the agreement plot (Fig. 1) and to the higher values

$\dagger$ Not for the condition of a statistical best fit. 
of the coefficients of variation (Table 2). Use of modifications similar to those suggested in $\$ 37$ improves the agreement considerably. Alternatively, one could try to determine the values of $k_{\mathrm{t}}, k_{\mathrm{b}}$ and $f_{\mathrm{bb}}$ which yield statistical best agreement with test results.

42. In the studies on estimating crack widths, the two approaches used-estimating the maximum width and estimating a width which has an accepted probability of being exceeded-are well known. ${ }^{10}$ The use of the latter involves the measurement of the widths of all the cracks that form so that dependable distributions and averages can be determined. In the case of slabs this could be more dificult than in beams because every crack that forms, being spread over a length, has to be measured at a large number of places and at every stage of loading. Another difficulty which is faced in two-way slabs is an experimental determination of the strain in the steel bar at the location of crack width measurement. We feel that more experiments and test data are required regarding the crack widths of two-way reinforced concrete slabs so that dependable prediction methods can be developed for such cases.

\section{References}

6. Clark L. A. Flexural cracking in slab bridges. Cement and Concrete Association, London, 1973, Technical report 42.479.

7. Srinivasa Rao P. and Subrahmanyam B. V. Cracking and ultimate strength of one-way slabs reinforced with welded wire fabric. Indian Concr.J., 1971, 45, Mar., $115-121,139$.

8. KULKARNI A. B. Strength and behaviour of two-way rectangular reinforced concrete slabs. PhD thesis, Indian Institute of Science, Bangalore, 1976.

9. HAWkins N. M. et al. Influence of column rectangularity on the behaviour of flat plate structures. Cracking, deflection and ultimate load of concrete slab systems. American Concrete Institute, Detroit, 1971, SP 30, 127-146.

10. DesayI P. Cracking of reinforced and prestressed concrete members. Indian Concr.J., 1976, 50, May, 146-150 and 1976, 50, June, 187-190. 